\title{
Soluble and insoluble lithium dust in the EPICA DomeC ice core-Implications for changes of the East Antarctic dust provenance during the recent glacial-interglacial transition
}

\author{
Marie-Louise Siggaard-Andersen ${ }^{\mathrm{a}, \mathrm{b}, *}$, Paolo Gabrielli ${ }^{\mathrm{c}, \mathrm{d}}$, Jørgen Peder Steffensen ${ }^{\mathrm{b}}$, \\ Trine Strømfeldt ${ }^{\mathrm{b}}$, Carlo Barbante ${ }^{\mathrm{c}}$, Claude Boutron ${ }^{\mathrm{d}}$, Hubertus Fischer ${ }^{\mathrm{a}}$, Heinz Miller ${ }^{\mathrm{a}}$ \\ a Alfred Wegener Institute for Marine and Polar Research, Columbusstrasse, 27568 Bremerhaven, Germany \\ ${ }^{\mathrm{b}}$ Ice and Climate, Niels Bohr Institute, University of Copenhagen, Juliane Mariesvej 30, 2100 Kbh Ø, Denmark \\ c Department of Environmental Sciences, University of Venice, Ca' Foscari, I-30123 Venice, Italy \\ ' Laboratoire de Glaciologie et Geophysique de l' Environnement (UMR CNRS-UJF 5183), 54 rue Moliere, Domaine Universitaire, BP 96, 38402 \\ Saint Martin d' Heres cedex, France
}

Received 21 September 2005; received in revised form 6 March 2007; accepted 11 March 2007

Available online 16 March 2007

Editor: G.D. Price

\begin{abstract}
Continental dust impurities in Antarctic ice provide information on climate changes in the dust source areas and on past atmospheric circulation. We investigated records of dust species from the last $45 \mathrm{ka}$ in the East Antarctic EPICA DomeC (EDC) ice core with special emphasis on the lithium (Li) content of dust. We obtained two complementary Li-records using a new Ion Chromatography (IC) technique in line with Inductively Coupled Plasma-Sector Field Mass Spectroscopy (ICP-SFMS). Concentrations of soluble $\mathrm{Li}\left(\mathrm{Li}^{+}\right)$were obtained using IC, while total concentrations of $\mathrm{Li}\left(\mathrm{Li}_{T}\right)$ were obtained using ICP-SFMS, providing an ideal opportunity to investigate the soluble and insoluble chemistry of Li in East Antarctic dust over the last glacialinterglacial transition. The records show that changes in the solubility of $\mathrm{Li}$ are associated with climatic changes. For the late glacial period and the Antarctic Cold Reversal (ACR) a large fraction, up to 75\%, of the $\mathrm{Li}_{T}$ content is present as insoluble minerals whereas for the Holocene period it seems that $\mathrm{Li}$ is present mainly as soluble salts $\left(\mathrm{Li}^{+}\right)$. We compared the concentrations of $\mathrm{Li}^{+}$with the concentrations of $\mathrm{Ca}^{2+}$ and the mass and size characteristics of the dust, which were obtained using Coulter Counting (CC). Furthermore we compared the concentrations of $\mathrm{Li}_{T}$ with the concentrations of $\mathrm{Ba}_{T}$. Our analysis suggests that the changes in solubility of Li along the EDC ice core are related to changes in compositions of the dust minerals. During the late glacial period, changes in the dust composition is characteristic of variations in the strength of the atmospheric circulation, while changes over the last glacial-interglacial transition are indicative of a change in the major dust source areas. The dust characteristics for the glacial and the Holocene periods indicate two different dust types. The glacial dust type partly disappeared after the ACR, while the Holocene dust type appeared significantly after around $16 \mathrm{ka} \mathrm{BP}$ and became dominant after the ACR. The relative increase in the Holocene dust type at the glacial-interglacial transition could be due to changed conditions in the potential source area or to changed patterns of atmospheric circulation, resulting in enhanced transport from a source area that was different from the glacial source areas.
\end{abstract}

(C) 2007 Elsevier B.V. All rights reserved.

Keywords: lithium; EPICA; Antarctica; eolian dust; last transition; climate

\footnotetext{
* Corresponding author. Niels Bohr Institute, Juliane Mariesvej 30, 2100 Copenhagen Ø, Denmark. Tel.: +45 35320561; fax: +45 35365357.

E-mail address: mlsa@gfy.ku.dk (M.-L. Siggaard-Andersen).
} 


\section{Introduction}

Aeolian dust deposits contain important information on past atmospheric dust transport and on dust mobilization in the source areas. In particular, dust deposited onto the East Antarctic Plateau represents a tracer for long range atmospheric dust transport over the Southern Ocean, which is believed to play a central role in the global $\mathrm{CO}_{2}$ budget through fertilization with iron rich dust and the consequent uptake of atmospheric $\mathrm{CO}_{2}$ by the ocean [1]. Detailed analysis of dust impurities in East Antarctic ice cores has been performed in order to obtain information on their concentrations and size characteristics $[2,3]$, mineralogy [4], element composition [5], and isotope composition [6]. Many new high resolution records of dust species have been obtained from the recently recovered EPICA Dome C (EDC) ice core [7], providing an ideal database to investigate, in detail, temporal changes in East Antarctic dust. Isotope analyses ( $\mathrm{Nd}$ and $\mathrm{Sr}$ ) of glacial dust from East Antarctic ice cores have identified Patagonia (Argentina) as the main glacial dust source area, with possible additional contributions from South Africa or Australia [6,8]. Recent analyses on East Antarctic ice cores are confirming a Patagonian origin for dust during glacial times [9], while for interglacial periods other source locations, such as Eastern Australia in particular, may have contributed to a more important extent [10].

Dust concentrations in the EDC ice core decreased by a factor of 50 from $790 \mathrm{pbb}$ (parts per billion) at the Last Glacial Maximum (LGM) to $15 \mathrm{pbb}$ during the Holocene period [3]. In general, concentrations of dust species in polar ice cores have decreased during warm periods, partly due to weakened transport [11], and partly to decreased dust mobilization in the source area as a result of locally increased humidity and vegetation cover [12]. Also changes in particle size characteristics are associated with climate changes and in particular to changes in conditions for long range atmospheric transport. For instance, in Greenland ice cores, particle size distribution modes (size modes in the following) are small during warm periods when atmospheric transport becomes less vigorous [13]. However, a contrasting increase in the particle size mode at the transition from the Last Glacial Maximum (LGM) to the Holocene was observed in the EDC ice core [3] and was explained as an effect of more favorable conditions for transport of dust to East Antarctica in the Holocene compared to the LGM [14]. This hypothesis was recently supported by the identification in the EDC ice core of possible inputs of volcanic Ir and Pt from coastal Antarctic areas exclu- sively during warm periods [15]. Other contradictions about atmospheric transport from Patagonia to East Antarctica during the LGM have resulted from atmosphere coupled general circulation model simulations [16] and back trajectory analysis [17], leaving many open questions about changes in the southern hemispheric dust cycle during the last glacial-interglacial transition.

Here we present a detailed investigation of the chemical and physical properties of the EDC dust material over the last $45 \mathrm{ka}$ with a special emphasis on $\mathrm{Li}$, which has peculiar geochemical properties and therefore can provide new information for a better understanding of the changes in the dust cycle during the last glacial-interglacial transition. Li exists in the environment at trace concentrations, with an average abundance in the upper crust of 22 ppm (parts per million) [18]. In addition, Li is relatively insoluble in water, and fits poorly into most mineral structures, which is why pure Li minerals are rare, however they can be found for example in Western Australia, where Li-minerals (pegmatite) are mined. On the other hand, the solubility of Li increases largely with increasing temperature, why Li can be very mobile during rockwater interactions and tends to accumulate in clay sediments, or in evaporite deposits. For instance, the salt lakes of the Bolivian Altiplano constitute a major deposit of Li-salts.

Concentrations of total $\mathrm{Li}\left(\mathrm{Li}_{T}\right)$ were previously measured in the East Antarctic Vostok ice core [19]. Low concentrations in the order of a few $\mathrm{pg} \mathrm{g}^{-1}$ were found during interglacial periods and high concentrations (between 40 and $100 \mathrm{pg} \mathrm{g}^{-1}$ ) during glacial periods. Based on enriched amounts of Li compared to other crustal species they concluded that the atmospheric cycle of Li was influenced by sources other than soil dust during warmer periods, or alternatively these changes in Li amounts during warm periods were in part linked with changes in the dust source areas, or physical soil conditions (variations in humidity), or transport processes (gravitational settling) between glacial and interglacial periods.

Using a new Ion Chromatography (IC) technique [20], we obtained the first Antarctic record of soluble Li $\left(\mathrm{Li}^{+}\right)$from the EDC ice core. A complementary record of the total amount of $\mathrm{Li}$ (soluble plus insoluble, $\mathrm{Li}_{T}$ ) was obtained using Inductively Coupled Plasma-Sector Field Mass Spectrometry (ICP-SFMS) [19]. A comparison of the two Li records offers an ideal opportunity to investigate soluble and insoluble behavior of $\mathrm{Li}$ in Antarctic ice. Complementary analysis of $\mathrm{Ca}^{+}, \mathrm{Ba}_{T}$, dust mass and size characteristics were performed. Hereby we 
obtained information on changes in the Li enrichment factor and how these changes are related to changes in dust composition, which could help with the understanding of possible changes in weathering in the dust source area, changes in location of the dust source and changed conditions for transport.

\section{Data and experimental methods}

\subsection{IC analysis of $\mathrm{Li}^{+}$and $\mathrm{Ca}^{2+}$}

Ion Chromatography (IC) was used for simultaneous analysis of a variety of simple soluble ions such as $\mathrm{SO}_{4}^{2-}$, $\mathrm{NO}_{3}^{-}, \mathrm{Ca}^{2+}$ and $\mathrm{Na}^{+}$[21]. Using a new IC technique [20] $\mathrm{Li}^{+}$was detected in addition to the other ions.

From the top $588 \mathrm{~m}$ of the EDC ice core, $55 \mathrm{~cm}$ long strips for IC analysis were cut in the field and distributed between 5 European laboratories, where the strips were manually decontaminated, using microtome knives, and cut into 2.5 or $5 \mathrm{~cm}$ sub-samples before they were melted and analyzed. For the depth interval from $588 \mathrm{~m}$ to $788 \mathrm{~m}$, samples for IC analysis were collected from contamination free excess melt water during continuous flow analysis [21]. The sample depth interval for these samples varies roughly between $10 \mathrm{~cm}$ and $50 \mathrm{~cm}$ depending on the amount of excess melt water from the flow analysis. In this work we present concentrations of $\mathrm{Li}^{+}$and $\mathrm{Ca}^{2+}$ in 1448 samples from the top $788 \mathrm{~m}$ of the EDC ice core, measured at the Department of Geophysics, University of Copenhagen, where the new IC technique was developed for the detection of $\mathrm{Li}^{+}$in trace amounts. This record represents discontinuous $55 \mathrm{~cm}$ sections of the core. The amount of data from the top $200 \mathrm{~m}$ of the ice core are limited due to lack of analyses in this part. Based on repeated measurements of standard solutions, the precision of the $\mathrm{Li}^{+}$concentrations was found to be better than $10 \%$ for the whole range of measured $\mathrm{Li}^{+}$concentrations. The analytical detection limit for $\mathrm{Li}^{+}$was around $1 \mathrm{pg} \mathrm{g}^{-1}\left(10^{-12} \mathrm{~g}\right.$ per g of ice). Process blanks for IC measurements were made from a rod of frozen ultrapure water, which were manually decontaminated with a microtome knife. A small amount of lithium was detected in all these blanks - on average $1 \mathrm{pg} \mathrm{g}^{-1}$, probably due to contamination from the plastic tube in which the ice rod was frozen. The amount of $\mathrm{Li}$ detected in the process blanks was, however, much lower than the glacial concentrations and were sufficiently low enough to have no affect on the significance of the relatively low interglacial $\mathrm{Li}$ concentrations. The $\mathrm{IC} \mathrm{Ca}^{2+}$ record [22] was measured in parallel with a high resolution $\mathrm{Ca}^{2+}$ record obtained by Continuous Flow Analysis [23].

\subsection{Coulter Counting of insoluble particles}

Coulter Counting (CC) was used to estimate dust mass concentrations and highly resolved particle size characteristics as some IC samples from the top $588 \mathrm{~m}$ of the ice core had a sufficiently large volume to be analyzed this way. Between 4 and 6 samples from each sample bag, adding up to 222 samples, were analyzed for particle characteristics. Dust masses were evaluated based on the assumption that the particles are spherical with a mass density of $2.7 \mathrm{~g} \mathrm{~cm}^{-3}$. The major uncertainty in particle counting is due to the fact that particles in a liquid suspension are not homogeneously distributed, and they have a tendency to settle by gravity. However, repeated sample particle counting showed in most cases to have reproducibility better than $\pm 15 \%$. The CC data presented here were measured in parallel with the EDC dust data presented in [3]. The two data sets are mutually consistent.

\subsection{Analysis of $L i_{T}$ and $B a_{T}$ concentrations}

Inductively Coupled Plasma-Sector Field Mass Spectrometry (ICP-SFMS) was used for simultaneous analyses of a variety of trace elements. In the top $788 \mathrm{~m}$ of the EDC ice core 46 samples were analyzed using ICP-SFMS (the data are reported in [24]). For these analyses discrete $55 \mathrm{~cm}$ sample strips were decontaminated in ultra-clean environments at the Laboratoire de Glaciologie et Géophysique de l'Environnement, Grenoble, France. From each strip two adjacent samples with a length of about $20 \mathrm{~cm}$ were obtained. From each sample a $5 \mathrm{ml}$ aliquot was analyzed for trace elements at the Department of Environmental Science, University of Venice, Italy $[5,24,25]$. The detection limit for ICPSFMS was $1 \mathrm{pg} \mathrm{g}^{-1}$ which was sufficient for quantification of $\mathrm{Li}_{T}$ in the EDC ice core.

\section{Results}

\subsection{The $\mathrm{Li}^{+}$and $\mathrm{Li}_{T}$ records}

Both $\mathrm{Li}$ records $\left(\mathrm{Li}^{+}\right.$and $\left.\mathrm{Li}_{T}\right)$ in the EDC ice core follow climate changes with high concentrations during cold periods and low concentrations during warm periods (Fig. 1). In the Holocene, the concentrations of $\mathrm{Li}^{+}$seem to exceed the concentrations of $\mathrm{Li}_{T}$, which may be a result of analytical imprecision since concentrations in these samples are very low at around a few $\mathrm{pg} \mathrm{g}^{-1}$, which is close to the detection limit of $1 \mathrm{pg} \mathrm{g}^{-1}$ for both analytical techniques. Both $\mathrm{Li}$ concentrations show variations in line with changes in dust concentrations. 


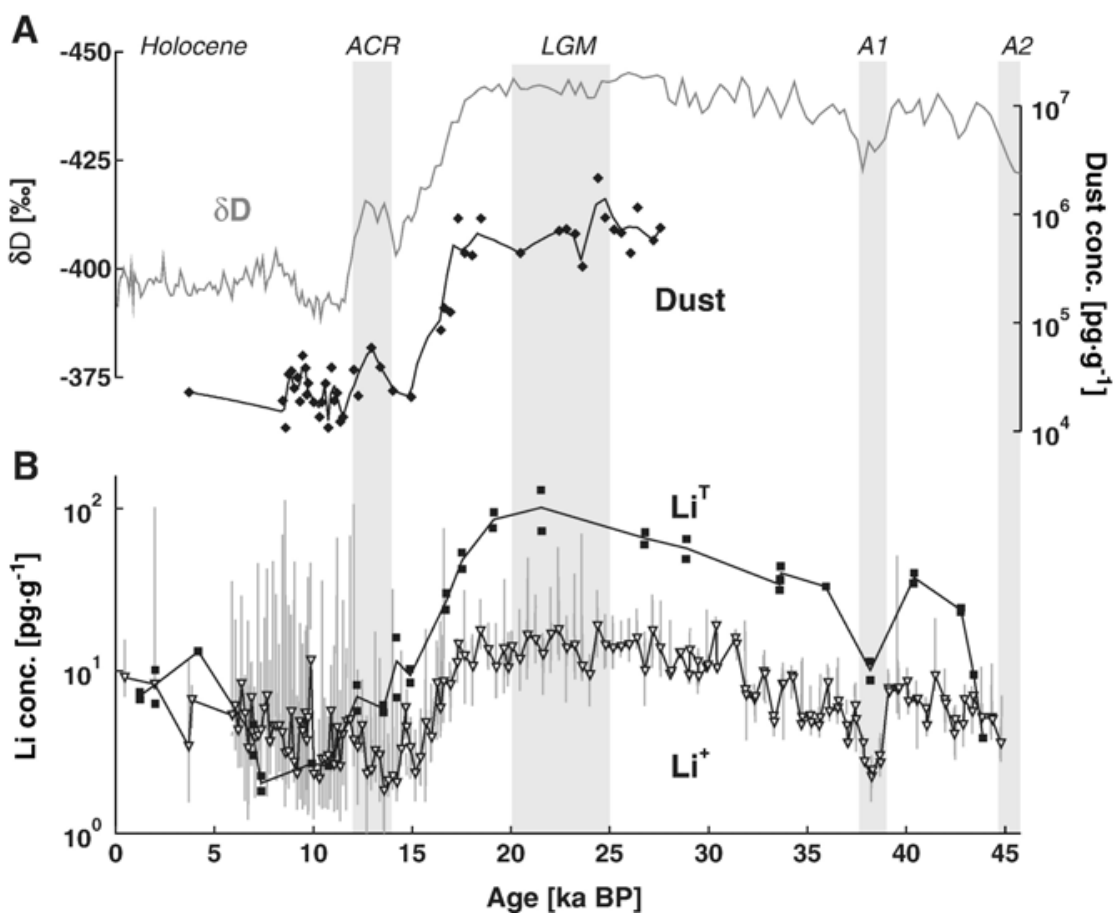

Fig. 1. (A) on the left axis (reversed for comparisons) is the EDC ice core record of Deuterium $(\delta \mathrm{D})$ over the last $45 \mathrm{ka}$ from [36]. On the right axis is shown actual dust mass concentrations analyzed using CC on excess IC sample volumes from the top $588 \mathrm{~m}$ of the ice core. The records are shown on the EDC-1 age scale [31], which was recommended for the time period of the last 45 ka until most recently, where the EDC-3 age scale [37] has been established. The differences between the EDC-1 and EDC-3 age scales are small and the use of EDC-1 has no effect on the discussions of this paper. The $\delta \mathrm{D}$ curve indicates East Antarctic temperature variations over the Holocene period and the later part of the last glacial, including the Last Glacial Maximum (LGM) at 20-25 ka BP and the Antarctic warming event, A1, around $38 \mathrm{ka} \mathrm{BP}$. Also the Antarctic warming, A2, around $45 \mathrm{ka}$ BP is seen in the right most part of the curve. The last transition in East Antarctica is characterized by a warming trend between $19 \mathrm{ka}$ BP and $11 \mathrm{ka}$ BP, which was interrupted by the Antarctic Cold Reversal (ACR) 14-12.5 ka BP. (B) The two Li records obtained by, respectively, IC (grey lines; the black line with open triangles indicate the bag median values) and ICP-SFMS (black squares; the solid black line indicate the bag mean values) analysis are shown on a logarithmic axis. Bag-means and bag-medians represent respectively mean and median values over $55 \mathrm{~cm}$ ice core strips.

At the LGM the concentrations of $\mathrm{Li}^{+}$and $\mathrm{Li}_{T}$ are $\sim 25$ and $\sim 100 \mathrm{pg} \mathrm{g}^{-1}$, respectively. The concentrations of $\mathrm{Li}_{T}$ in the EDC ice core are very similar to previously determined $\mathrm{Li}_{T}$ concentrations of about 1-100 $\mathrm{pg} \mathrm{g}^{-1}$ in the East Antarctic Vostok ice core [19].

Insoluble trace elements in Antarctic ice are mainly related to insoluble mineral dust impurities [19], while soluble species are mainly of marine origin. However, certain fractions of soluble species are dissolved or leached from dust minerals. The sea salt contributions to the amounts of different soluble species are conventionally estimated on the basis of the sea water ratio of the target analyte to $\mathrm{Na}^{+}[26]$. The $\mathrm{Li}^{+} / \mathrm{Na}^{+}$mass ratio in sea water is $1.8 \times 10^{-5}$ [27] which is more than 10 times lower than the average $\mathrm{Li}^{+} / \mathrm{Na}^{+}$mass ratio of $2.1 \times 10^{-4}$ measured in the EDC ice core. We therefore can consider $\mathrm{Li}^{+}$as well as insoluble $\mathrm{Li}$ in the EDC ice core to be essentially mineral dust species. The variations in relative amounts of the two species therefore reflect changes in solubility of Li from mineral dust. A comparison of the two Li records shows that the soluble fraction of the Li content changes significantly along the record. For the glacial period a major fraction of the $\mathrm{Li}$ is insoluble whereas for the Holocene, it seems that all of the $\mathrm{Li}$ is soluble.

In the upper part of the record, $\mathrm{Li}^{+}$shows high spikes of up to $100 \mathrm{pg} \mathrm{g}^{-1}$. A closer inspection of the data shows that the changes in frequency and magnitude of the spikes are related to changes in sample time interval. Furthermore, the peak concentrations of the spikes in the Holocene samples exceed the peak concentrations in the glacial samples. From these observations, suggesting that the spikes are absent in LGM due to the low sample resolution, it is unlikely that the spikes are artefacts introduced during sampling and analysis. Although it is difficult to explain the occurrence of high spikes in the Holocene part of the record, we believe they represent impurities in the ice; 
not an artefact introduced during sampling or measurements. In fact, the sample time intervals for the manually cut IC samples are 1-2 yr for the Holocene and 4.0-4.5 $\mathrm{yr}$ for the glacial period. For the ICPSFMS samples, the sample time intervals were significantly longer, 6-8 yr for the Holocene and 15$18 \mathrm{yr}$ for the glacial period. This, together with the much smaller number of samples measured using ICPSFMS could be a reason why the spikes do not appear in the ICP-SFMS record. The spikes in the $\mathrm{Li}^{+}$record may be reflecting particular geochemical properties of $\mathrm{Li}$ either in the dust source region or in the ice matrix. Changing humidity in local areas at the dust source could result in short-term exposures of lake sediments or evaporates highly enriched in Li. Another possibility could be short-term occurrences of changed wind trajectories carrying $\mathrm{Li}$ enriched dust from a different source location; for example, the area of Bolivia Altiplano, South America, at $20{ }^{\circ} \mathrm{S}$, where great salt planes contain evaporite with extremely high amounts of Li. Alternatively, the $\mathrm{Li}^{+}$spikes could be a result of special properties of $\mathrm{Li}^{+}$in the ice matrix. $\mathrm{Li}^{+}$may have the ability to migrate very fast in the ice, due to its small ion radius, and to accumulate at locations favorable for Li. However, no observations so far can support this hypothesis. High-resolution chemical analyses of ice samples, using e.g. an ICP-MS technique, may potentially shed more light on the source to the Li-spikes.

\subsection{Dust composition}

Aerosol dust is rather inhomogeneous, consisting of particles of a wide size range $(0.1-10 \mu \mathrm{m}$ in diameter) representing a variety of mineral types, characteristic for a particular dust source area. The clay minerals are relatively small, while quartz grains are relatively large. Fractionation of mineral dust during long-range atmospheric transport is a well-known phenomenon (e.g. $[28,29])$. Dust size and mineral characteristics are modified over time in the atmosphere due to different atmospheric life-times for different fractions of the aerosol particles. In a moving air parcel the concentrations $C=C(t)$ for an aerosol species with atmospheric life-time $\tau$, can be expressed as a function of time, $t[30]$ :

$C=C_{0} \cdot \exp \left[-\left(t-t_{0}\right) \cdot \tau^{-1}\right]$

or equivalently:

$\ln [C]=\ln \left[C_{0}\right]-\left(t-t_{0}\right) \cdot \tau^{-1}$ where $C_{0}$ is the air concentration of the species at an earlier time $t_{0}$. For two different species $\mathrm{A}$ and $\mathrm{B}$ we obtain from Eq. (2)

$\ln \left[C_{\mathrm{A}}\right]=\frac{\tau_{\mathrm{B}}}{\tau_{\mathrm{A}}} \cdot \ln \left[C_{\mathrm{B}}\right]+$ const.

and further for the ratio between the two species:

$\ln \left[C_{\mathrm{A}} / C_{\mathrm{B}}\right]=\left(\frac{\tau_{\mathrm{B}}}{\tau_{\mathrm{A}}}-1\right) \cdot \ln \left[C_{\mathrm{B}}\right]+$ const.

Assuming that a major climate influence on air concentrations are changes in transport time, it follows from Eq. (4) that the logarithm of the ratio between two species $\mathrm{A}$ and $\mathrm{B}$ has a linear relationship with logarithmic concentrations of species B. For the relative comparison purpose in the following, we make the assumption that air concentrations of aerosol species are well represented by ice concentrations. Hereby we are neglecting possible effects on concentrations from varying snow accumulation rates. In fact, these variations are small, a factor of $\sim 2$ between the LGM and the Holocene [31], compared to variations in dust concentrations, which are a factor of 50 between the LGM and the Holocene [3], and in $\mathrm{Li}^{+}$concentrations, which vary by a factor of 10 between the LGM and the Holocene. Furthermore we did not correct for the sea salt contributions of the different species, which in case of $\mathrm{Ca}^{2+}$ is not a negligible amount: $24 \% \pm 10 \%$ for the Holocene, and $8 \% \pm 2 \%$ for the glacial period, calculated using the $\mathrm{Na}^{+}$concentrations as a sea salt proxy, however this does not affect our results.

Deviations from a linear relationship between logarithmic ice concentrations signifies influences on air concentrations other than transport time. Fig. 2A shows the relationship between logarithmic $\mathrm{Li}^{+} / \mathrm{Ca}^{2+}$ ratios and $\mathrm{Ca}^{2+}$ concentrations. During the glacial period the $\mathrm{Li}^{+} / \mathrm{Ca}^{2+}$ ratios are nearly constant at around $3 \times 10^{-4}$, which is similar to the $\mathrm{Li} / \mathrm{Ca}$ mass ratio in the upper continental crust [18]. In contrast, during the Holocene there is no correlation between the $\mathrm{Li}^{+} / \mathrm{Ca}^{2+}$ ratio and $\mathrm{Ca}^{2+}$ and the relative concentrations of $\mathrm{Li}^{+}$are markedly higher, with $\mathrm{Li}^{+} / \mathrm{Ca}^{2+}$ ratios of up to $10^{-2}$, which can be explained in two different ways, as an enrichment of $\mathrm{Li}$ in the Holocene dust, or as an acidity effect, enhancing the solubility of Li.

In order to investigate variations in the relative $\mathrm{Li}_{T}$ amounts in the dust, we use here the concentration of $\mathrm{Ba}_{T}$ as a continental tracer. In order to assess the importance of the rock and soil dust contribution for $\mathrm{Li}$ we calculated crustal enrichment factors $(\mathrm{EFc})$ for each depth. An EFc is defined as the concentration ratio of a 
A

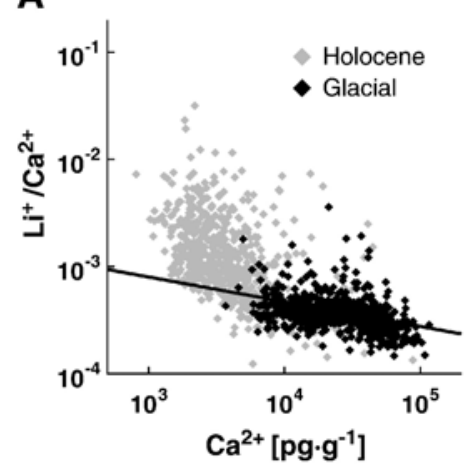

C

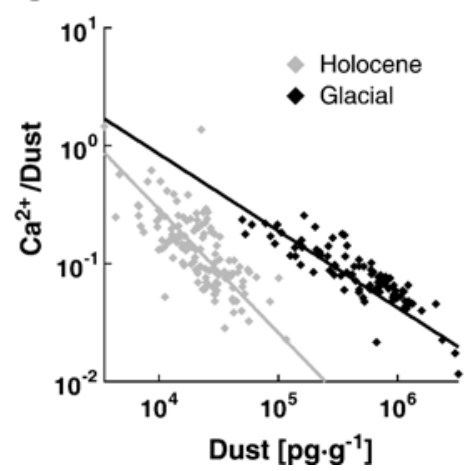

B

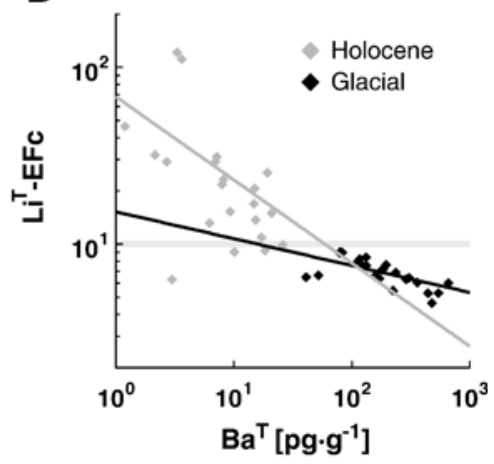

D

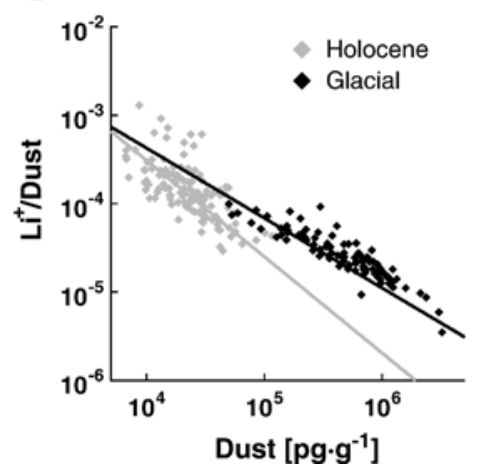

Fig. 2. Analysis of dust species for the Holocene (grey points) and the glacial (black points) periods. (A) $\mathrm{Li}^{+} / \mathrm{Ca}^{2+} \mathrm{mass}^{2}$ ratios versus $\mathrm{Ca}^{2+}$ concentrations (in $\mathrm{pg} \mathrm{g}^{-1}$ ). (B) Crustal enrichment factors $\left(\mathrm{EFc}\right.$ ) for $\mathrm{Li}_{T}$ evaluated using $\mathrm{Ba}_{T}$ concentrations as a crustal indicator (see Eq. (5)). The thick horizontal line indicate $\mathrm{EFc}=10$, which we consider to be a maximum value for soil dust. (C) $\mathrm{Ca}^{2+} /$ Dust mass-ratio versus dust massconcentration. (D) $\mathrm{Li}^{2+} /$ Dust mass-ratio versus dust mass-concentration.

given element to that of $\mathrm{Ba}_{T}$ or $\mathrm{Ca}^{2+}$ (which are good proxies for rock and soil dust). For example, the EFc for $\mathrm{Li}$ with respect to $\mathrm{Ba}$ is thus:

$\mathrm{EFc}=\frac{[\mathrm{Li}]_{\text {ice }} /[\mathrm{Ba}]_{\text {ice }}}{[\mathrm{Li}]_{\text {crust }} /[\mathrm{Ba}]_{\text {crust }}}$

where $[\mathrm{Li}]_{\text {crust }} /[\mathrm{Ba}]_{\text {crust }}=22 \mathrm{ppm} / 668 \mathrm{ppm}=0.033$ according to data for the upper continental crust given by [18]. Despite the fact that the composition of rock and soil dust reaching Antarctica might significantly differ from the composition of the mean upper crust, $\mathrm{EFc}$ values close to unity (up to $\sim 5$ ) will indicate that the corresponding elements mainly originate from rock and soil dust. Using $\mathrm{Ba}$ as a crustal indicator we may expect larger $\mathrm{EFc}$ values (up to $\sim 10$ ) for soil dust since a fraction of $\mathrm{Ba}$ is strongly bounded to silicates and might be not detected by ICP-SFMS [19]. It should however be emphasized that the choice of other crustal compositions would not make any significant differences in the interpretation. Conversely, values significantly larger than $\sim 10$ will most likely indicate a significant contribution from other natural sources such as salt deposits and volcanic eruptions. Fig. 2B shows the relationship between $\mathrm{Li}_{T} \mathrm{EFc}$ values, calculated according to Eq. (5), versus $\mathrm{Ba}_{T}$ concentrations. The EFc values are all between 5 and 10 for the glacial period i.e. within the limit for soil dust, while for the Holocene period all EFc values are higher than 10. The Holocene EFc values are very similar to $\mathrm{EFc}$ values measured in an ice core from Bolivia, South America [32], where the salt lakes of Bolivia Altiplano are likely to contribute significantly to the ice core Li content. The glacial data points in Fig. 2B show a significant decreasing trend $\left(R^{2}=0.47\right.$ for logarithmic data) with increasing $\mathrm{Ba}_{T}$ concentrations, which indicates a modification of the dust during transport with a longer atmospheric lifetime for $\mathrm{Li}_{T}$ than for average dust $\left(\mathrm{Ba}_{T}\right)$. For the Holocene, the $\mathrm{Li}_{T}-\mathrm{EFc}$ is above the trend line for the glacial samples. Comparing Fig. 2B with A where the relative amount of $\mathrm{Li}^{+}$is much higher during the Holocene period, we see that the excess $\mathrm{Li}_{T}$ recorded in the Holocene is due the enhanced relative amounts of $\mathrm{Li}^{+}$. 
Fig. 2C and $\mathrm{D}$ shows respectively the ratios $\mathrm{Ca}^{2+} /$ dust mass and $\mathrm{Li}^{+} /$dust mass versus dust mass concentrations (given in $\mathrm{pg} \mathrm{g}^{-1}$ ). The $\mathrm{Ca}^{2+}$ /dust mass and $\mathrm{Li}^{+} /$dust mass ratios versus dust mass show decreasing trends both for the Holocene and for the glacial period. However, for the $\mathrm{Ca}^{2+}$ /dust mass ratio (Fig. 2C) the trends for the Holocene and glacial period are markedly different, with relatively low $\mathrm{Ca}^{2+} /$ dust mass ratios for the Holocene, while for the $\mathrm{Li}^{+} / \mathrm{dust}$ mass ratio, the trends for the glacial period and the Holocene are very similar. To understand this difference one should consider that the changes in soluble chemistry $\left(\mathrm{Li}^{+}\right.$and $\left.\mathrm{Ca}^{2+}\right)$ along the ice core record could be related to varying acid chemistry in the ice, dissolving different fractions of the dust minerals. Antarctic ice is mainly acidic due to relatively high ice core concentrations of sulphuric acid and nitric acid [33]. However, $\mathrm{Ca}^{2+}$ represents an alkaline constituent $\left(\mathrm{CaCO}_{3}\right)$ that reduces acidity and limits the acidity effects on freshly deposited aerosol [34]. Reactions between dust aerosols and aerosols of sulfuric or nitric acid during atmospheric transport is also a possibility (e.g. [8]). So we may expect different acidity effects on dust during different climate periods. However, melted ice samples from Antarctica are always acidic, so we can assume that all the samples analyzed are subjected to a maximum degree of acidity effect during sample preparation. Furthermore, the trend for the $\mathrm{Ca}^{2+} /$ dust mass ratio shiftings towards relatively lower values during the transition, which cannot be a result of an acidity effect, while the trend for the $\mathrm{Li}^{+} /$dust mass ratio is rather constant over the record. In addition, the higher $\mathrm{Li}^{+} / \mathrm{Ca}^{2+}$ ratios during the Holocene compared to those during the glacial period (Fig. 2A) are associated with an increase in the trend for the $\mathrm{EFc}$ (Fig. 2B), indicating that changes in the soluble fraction reflect changes in the dust composition rather than being a result of fluctuations in the acid chemistry. This is further supported by the opposite behavior of Fe that seems more soluble during the LGM than during the Holocene [35].

In order to summarize our results, average values for the Holocene (0-11 ka BP) and the late glacial period (20-45 ka BP) of the parameters investigated above are shown in Table 1.

\subsection{Particle size analysis}

Results from our particle analysis are shown in Fig. 3. The volumes (masses), $V$, of dust particles are nearly log-normally distributed with respect to particle diameter, $d$. Size distributions of insoluble dust particles are characterized by the modes ( $\mu$; diameter) and the relative
Table 1

Average values (avg) and standard deviations (std) for the Holocene, 0-12 ka BP and for the late glacial period, which cover the time interval of 20-45 ka BP in the first four rows and of 20-27 ka BP in the last four rows

\begin{tabular}{lcc}
\hline & Holocene avg (std) & Late glacial avg (std) \\
\hline $\mathrm{Li}^{+}\left[\mathrm{pg} \mathrm{g}^{-1}\right]$ & $7(11)$ & $11(7)$ \\
$\mathrm{Li}_{\text {(bag median) }}^{+}\left[\mathrm{pg} \mathrm{g}^{-1}\right]$ & $5(2)$ & $9(4)$ \\
$\mathrm{Li}_{T}\left[\mathrm{pg} \mathrm{g}^{-1}\right]$ & $6(4)$ & $41(29)$ \\
$\mathrm{Li}_{T}-\mathrm{EFc}$ & $28(30)$ & $7(1)$ \\
Dust mass $10^{3}\left[\mathrm{pg} \mathrm{g}^{-1}\right]$ & $26(11)$ & $791(46)$ \\
$\mathrm{Size}$ mode $[\mu \mathrm{m}]$ & $1.9(0.2)$ & $1.8(0.2)$ \\
$\mathrm{Li}^{+} /$Dust $\left[10^{-5}\right]$ & $21(23)$ & $3(2)$ \\
$\mathrm{Ca}^{2+} /$ Dust & $0.18(0.21)$ & $0.08(0.04)$ \\
\hline
\end{tabular}

standard deviation $(\sigma=\operatorname{std}-\log (\mu))$ of the normal fit to the $\partial V / \partial \log (d)$ distribution. In Fig. 3A is seen a decrease in particle size mode over a few ka at the beginning of the last transition. But then at $16 \mathrm{ka} \mathrm{BP}$, the size mode abruptly increases, which is consistent with previous observations in the EDC ice core [3], and opposite to what would be expected on the basis of other observations (e.g. in Greenland ice cores [13]), where warmer climate conditions are associated with a smaller particle size mode. Opposite changes in particle size modes at different East Antarctic sites were previously observed and explained as a regional transport effect involving a vertical fractionation process [14]. However, as seen in Fig. 3A the increase in particle size mode is associated with an increase in the standard deviation, $\sigma$, of the lognormal size distribution, pointing to a mixed dust type for the Holocene.

In order to obtain a better understanding of the glacial to interglacial changes in the particle characteristics, we analyzed different dust size fractions separately. The Coulter Counter sorts the particle counts into size fractions corresponding to the 256 instrumental channels, from which we obtained time series for each size interval. Each series was then correlated with the series of $\mathrm{Li}^{+}$and $\mathrm{Ca}^{2+}$ concentrations. The Holocene and glacial sub-series were correlated separately. The maximum particle size to be significantly counted can be determined on the basis of the influence of Poisson statistics on the particle counts. This influence resulted in a $>10 \%$ counting error for particles larger than $6.6 \mu \mathrm{m}$ for the glacial series, and for particles larger than $3.5 \mu \mathrm{m}$ for the Holocene series. The minimum particle size to be counted depends on the sensitivity for CC and is set to $0.8 \mu \mathrm{m}$ in diameter. For the glacial period the observed correlation curves for $\mathrm{Li}^{+}$and $\mathrm{Ca}^{2+}$ are nearly proportional (Fig. 3C). $\mathrm{Ca}^{2+}$ correlates best with particles around $1 \mu \mathrm{m}$ in diameter and $\mathrm{Li}^{+}$correlates best with particles around $0.8-1.0 \mu \mathrm{m}$ in diameter 

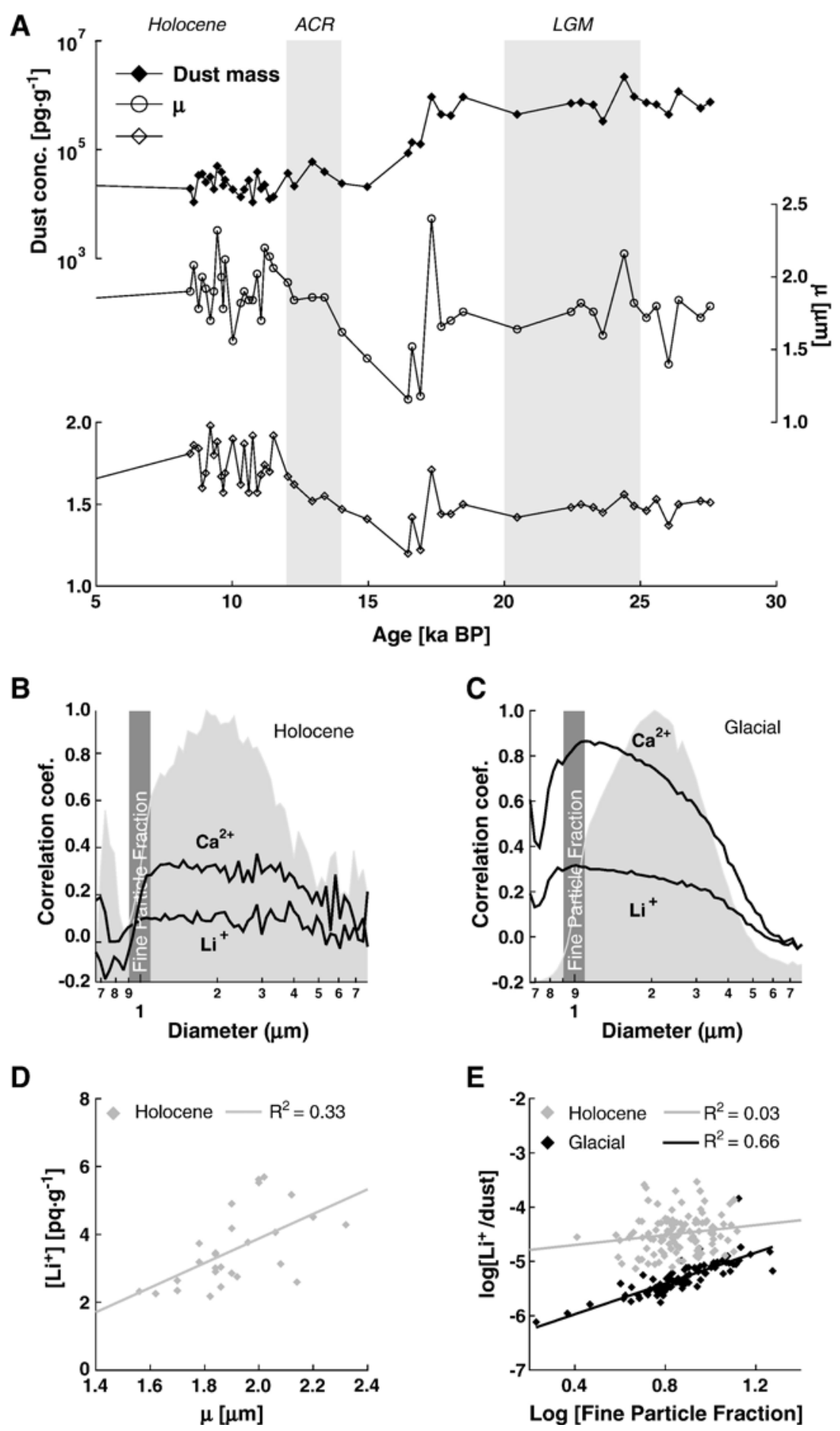

Fig. 3. (A) dust mass concentrations (in $\mathrm{pg} \mathrm{g}^{-1}$ of ice) together with the particle size mode $(\mu)$ and standard deviation $(\sigma)$ of a log-normal size distribution. (B, C) Correlation coefficients for correlations between particle size fractions and respectively $\mathrm{Li}^{+}$and $\mathrm{Ca}^{2+}$ for the $\mathrm{Holocene}(\mathrm{B})$ and the glacial (C) periods. The solid grey curve indicates the size distribution of particle counts. The grey bar at around $1 \mu \mathrm{m}$ indicates the Fine Particle Fraction used in panel (E). (D) Bag medians of $\mathrm{Li}^{+}$concentrations (in $\mathrm{pg} \mathrm{g}^{-1}$ of ice) versus bag means of particle size mode for the Holocene period (bag-means and bag-medians represent respectively mean and median values over $55 \mathrm{~cm}$ ice core strips). (E) Logarithmic $\mathrm{Li}^{+} / \mathrm{dust}$ mass ratios versus logarithmic Fine Particle Fraction values (in \%), which we have chosen to be the mass fraction of particles in the size range between 0.9 and $1.1 \mu \mathrm{m}$ in diameter (marked with a grey bar in (B) and (D)). 
indicating that $\mathrm{Li}^{+}$and $\mathrm{Ca}^{2+}$ are both mainly related to the very small particles that usually are dominated by clay minerals [28]. For the Holocene series (Fig. 3B) correlations are limited because of less accuracy in the low concentration range both for particle counts and for IC measurements. However, using bag-medians (median sample value for a $55 \mathrm{~cm}$ ice core depth interval) for $\mathrm{Li}^{+}$concentrations and bag-averages (mean sample value for a $55-\mathrm{cm}$ ice core depth interval) for particle characteristics, there seems to be a significant increasing trend for $\mathrm{Li}^{+}$concentrations with increasing size mode for the Holocene (Fig. 3D), suggesting that $\mathrm{Li}^{+}$in this period is associated with larger particles. A relationship with very small particles for $\mathrm{Li}^{+}$during the glacial period is further confirmed by the increasing trend of the $\mathrm{Li}^{+} /$dust mass ratio against the mass fraction of particles in the $0.9-1.1 \mu \mathrm{m}$ diameter size fraction (Fig. 3E). $\mathrm{Ca}^{2+}$ has a similar relationship with the $0.9-1.1 \mu \mathrm{m}$ size fraction (not shown) during the glacial period. This investigation shows that the Li enrichment in the EDC ice core during the Holocene is associated with an abruptly and marked change in the behavior of the dust material at the last transition, indicating a major change in the composition of terrestrial dust.

\section{Discussion}

\subsection{Changes in dust composition during the late glacial period}

Changes in dust concentrations during the late glacial period in the EDC ice core (e.g. during the Antarctic warming A1 (Fig. 1)) has been explained in previous papers by changes in dust mobilization at the source $[3,23]$. However, the linear relationships between logarithmic concentrations of different dust species, for the period from $45 \mathrm{ka} \mathrm{BP}$ and around $16 \mathrm{ka} \mathrm{BP}$ (Fig. 2 ), indicate that the chemical and size characteristics of the dust to a large part is affected by modifications during transport, associated with changing airconcentrations. From our results, variations in dust concentrations during the late glacial period are therefore to a significant part resulting from changes in the strength of atmospheric circulation, pointing to a more efficient transport of dust to East Antarctica during the LGM than during A1.

\subsection{Glacial-interglacial contrasts}

While the changes in dust composition between 45 and $16 \mathrm{ka}$ BP shows systematic behavior which can be explained as an effect of changing transport times, probably combined with systematic climate changes in the dust source area, the changes at around $16 \mathrm{ka} \mathrm{BP}$ need a different explanation. A major decrease in source emission [23] and a vertical fractionation process locally [14] are previously proposed hypotheses, which may be supported by some of the observations that were done from the present analysis; for instance the $\mathrm{Ca}^{2+} /$ dust mass ratios in the Holocene are similar to the corresponding glacial ratios although concentrations in the ice core are much lower during the Holocene (Fig. 2C). This could indicate that transport modifications of the dust characteristics are similar during the glacial and the Holocene. However, other observations are not consistent with those hypotheses. The most striking one is the glacial-interglacial change in behavior of $\mathrm{Li}^{+}$, which for the glacial part is related to the small sized particle fraction, while in the Holocene part, increased $\mathrm{Li}^{+}$concentrations are associated with a large particle size mode (Fig. 3D and E). This contrast indicates a marked change in mineral composition of the dust at the last transition. In the glacial period, Li seems to be related to clay minerals that generally consist of very fine particles that can leach soluble species to natural waters, while in the Holocene dust, Li seems to be mostly soluble, suggesting that $\mathrm{Li}$ in that period is associated with other minerals, from evaporate deposits, for instance. Based on our studies on the dust in the EDC ice core we suggest that the Holocene and the glacial dust respectively represent two different dust materials probably related to different source areas. The observation of relatively weak correlations between dust species during the Holocene (Fig. 2) points to a mixed composition of different dust materials during the Holocene. This is further supported by the observation of an increased standard deviation of particle sizes during the Holocene (Fig. 3A).

According to the relationships in the glacial period between different dust species (Fig. 2A-D), we have matched the amplitudes of four different records on logarithmic scales (Fig. 4). Between $45 \mathrm{ka} \mathrm{BP}$ and $16 \mathrm{ka}$ $\mathrm{BP}$ the curves are lying on top of each other, illustrating a relationship between the species according to Eq. (3). After approximately $16 \mathrm{ka} \mathrm{BP}$, the curves start to diverge and from the end of the transition they are completely separate in the plot, illustrating the change in dust characteristics. While a Patagonian provenance of the glacial dust has been well documented (e.g. [14]), the Holocene dust may be characteristic for an additional dust source that, if present, was not important during the glacial period. Considering that the size characteristics change abruptly at around $16 \mathrm{ka} \mathrm{BP}$ while the decreasing trend in concentrations is constant, we suggest that the 


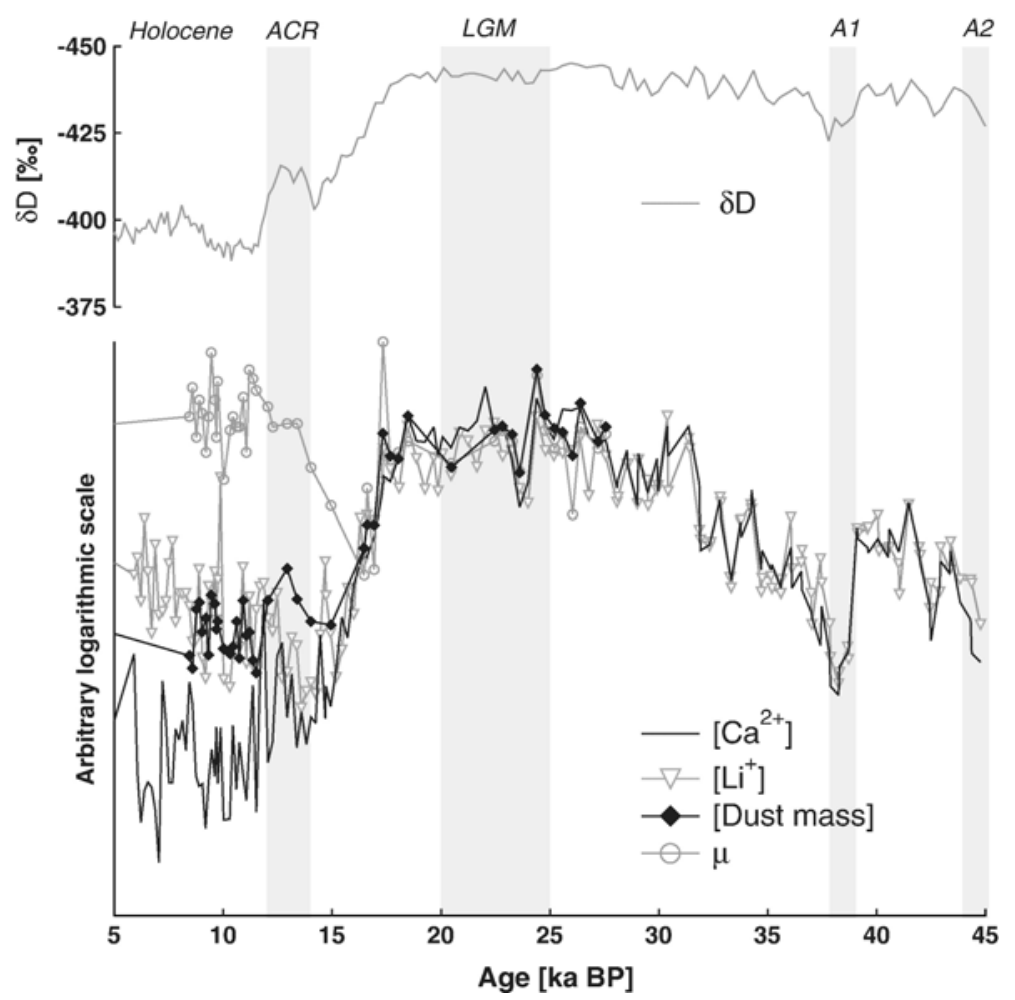

Fig. 4. Reconstruction of the change in particle characteristics over the transition in the EDC ice core. The top curve show the $\delta \mathrm{D}$ record on a reversed axis. Below that are the records of $\mathrm{Li}^{+}$bag median (grey line and open triangles), $\mathrm{Ca}^{2+}$ bag means (black line only), dust mass concentrations (line and solid diamonds) and size mode bag means ( $\mu$, line and open circles). The curves are shown on arbitrary logarithmic scales that are scaled to match over the glacial period.

amounts of the glacial dust type in the EDC ice core decreased, as expected, in line with the warming trend, while the relative amount of the Holocene dust increased abruptly at around $16 \mathrm{ka}$ BP due to some major changes in transport trajectories or in dust mobilization at a potential source area.

\section{Conclusions}

Based on the two complementary records of soluble and total $\mathrm{Li}$ from the EDC ice core we have made detailed studies of the chemical properties of the EDC ice core dust material. Our analyses take modifications of dust characteristics during atmospheric transport into account, and reveals a major change in the dust material at around $16 \mathrm{ka}$ BP. Our analyses have shown a high degree of complexity in the characteristics of East Antarctic dust and has demonstrated the importance of including many parameters in an analysis in order to avoid a misleading interpretation.

Using $\mathrm{Ba}$ concentrations as a crustal indicator we have shown that the dust is enriched in Li during the
Holocene, while a comparison between concentrations of $\mathrm{Ca}^{2+}$ and dust mass showed a relative depletion in the $\mathrm{Ca}^{2+}$ content during the Holocene. These observations rule out an effect from acidity on concentrations of the soluble dust species. Our analysis of dust size characteristics confirms previous observations by [3] of an increase in the dust size mode during the last transition. Further analysis of dust size fractions showed contrasting glacial-interglacial behavior. In the glacial dust, $\mathrm{Li}^{+}$and $\mathrm{Ca}^{2+}$ are well correlated and both are related to relatively small particles, which are likely to be clay minerals. In contrast, in the Holocene dust, $\mathrm{Li}^{+}$and $\mathrm{Ca}^{2+}$ are only weakly correlated, the $\mathrm{Li}$ content is to a larger part soluble, and high $\mathrm{Li}^{+}$ concentrations are associated with a large particle size mode. These properties indicate different dust materials in the EDC ice core for the glacial period and for the Holocene. The glacial dust has a well-defined mineral composition, which seems to be significantly affected by varying transport times from the Patagonian source location to the East Antarctic ice sheet. At around $16 \mathrm{ka}$ $\mathrm{BP}$, the characteristics of the dust material changed 
abruptly probably due to a change in the main source location.

Based on our analysis of the EDC ice core dust, we propose here that the glacial dust material partly disappeared from the air mass above Dome $\mathrm{C}$ by the end of the Antarctic Cold Reversal; possibly due to a weakened transport from Patagonia as the climate became warmer, while a different dust material was introduced to Dome $\mathrm{C}$ around $16 \mathrm{ka} \mathrm{BP}$ being in addition to the glacial dust material during the Antarctic Cold Reversal. The Holocene dust seems to be mixed between different dust types, probably representing different source areas. Future studies on transport of dust to East Antarctica might focus on the changes in the major dust source, occurring at around $16 \mathrm{ka} \mathrm{BP}$, in order to understand whether they are related to enhanced dust mobilization in a potential dust source area or to a change in the atmospheric flow pattern for East Antarctic dust.

\section{Acknowledgement}

This work is a contribution to the European Project for Ice Coring in Antarctica (EPICA), a joint European Science Foundation/European Commission scientific programme, funded by the EU (EPICA-MIS) and by national contributions from Belgium, Denmark, France, Germany, Italy, the Netherlands, Norway, Sweden, Switzerland and the United Kingdom. The main logistic support was provided by IPEV and PNRA (at Dome C) and AWI (at Dronning Maud Land). This is EPICA publication no. 168. The authors would like to thank Dr. Warren Cairns for useful comments to the manuscript and Niels Kjr for his assistance in the dust analyses.

\section{Appendix A. Supplementary data}

Supplementary data associated with this article can be found, in the online version, at doi:10.1016/j.epsl. 2007.03.013.

\section{References}

[1] A.J. Watson, D.C. Bakker, A.J. Ridgwell, P.W. Boyd, C.S. Law, Effect of iron supply on Southern Ocean $\mathrm{CO}_{2}$ uptake and implications for glacial atmospheric $\mathrm{CO}_{2}$, Nature 407 (6805) (2000) 730-733.

[2] J. Petit, J. Jouzel, D. Raynaud, N. Barkov, J.-M. Barnola, I. Basile, M. Bender, J. Chappellaz, M. Davis, G. Delaygue, M. Delmotte, V. Katlyakov, M. Legrand, V. Lipenkov, C. Lorius, L. Pépin, C. Ritz, E. Saltzman, M. Stievenard, Climate and atmospheric history of the past 420,000 years from the Vostok ice core, Antarctica, Nature 399 (6735) (1999) 429-436.
[3] B. Delmonte, J. Petit, V. Maggi, Glacial to Holocene implications of the new 27000-year dust record from the EPICA Dome C (East Antarctica) ice core, Clim. Dyn. 18 (8) (2002) 647-660, doi:10.1007/s00382-001-0193-9.

[4] A. Gaudichel, M. De Angelis, S. Joussaume, J.R. Petit, Y.S Korotkevitch, V.N. Petrov, Comments on the origin of dust in East Antarctica for present and ice age conditions, J. Atmos. Chem. 14 (1-4) (1992) 129-142.

[5] P. Gabrielli, A. Varga, C. Barbante, C. Boutron, G. Cozzi, V. Gaspari, F. Planchon, W. Cairns, S. Hong, C. Ferrari, G. Capodaglio, Determination of Ir and Pt down to the subfemtogram per gram level in polar ice by ICP-SFMS using preconcentration and a desolvation system, J. Anal. At. Spectrom. 19 (7) (2004) 831-837.

[6] F.E. Grousset, P.E. Biscaye, M. Revel, J.-R. Petit, K. Pye, S. Joussaume, J. Jouzel, Antarctic (Dome C) ice-core dust at 18 k.y. B.P.: Isotopic constraints on origins, Earth Planet. Sci Lett. 111 (1) (1992) 175-182.

[7] EPICA community members, Eight glacial cycles from an Antarctic ice core, Nature 429 (6992) 623-628.

[8] I. Basile, F. Grousset, M. Revel, J. Petit, P. Biscaye, N. Barkov, Patagonian origin of glacial dust deposited in east Antarctica (Vostok and dome c) during glacial stages 2, 4 and 6, Earth Planet. Sci. Lett. 146 (3-4) (1997) 573-589.

[9] B. Delmonte, I. Basile-Doelsch, J.-R. Petit, V. Maggi, M. RevelRolland, A. Michard, E. Jagoutz, F. Grousset, Comparing the EPICA and Vostok dust records during the last 220,000 years: stratigraphic correlation and provenance in glacial periods, Earth Sci. Rev. 66 (2004) 63-87.

[10] M. Revel-Rolland, P. De Deckker, B. Delmonte, P. Hesse, J.W. Magee, I. Basile-Doelsch, F. Grousset, D. Bosch, Eastern Australia: a possible source of dust in east Antarctica interglacial ice, Earth Planet. Sci. Lett. 249 (1-2) (2006) 1-13.

[11] J.-R. Petit, M. Briat, A. Royer, Ice age aerosol content from East Antarctic ice core samples and past wind strength, Nature 293 (5831) (1981) 391-394.

[12] I. Tegen, S. Harrison, K. Kohfeld, I.C. Prentice, M. Coe, M. Heimann, Impact of vegetation and preferential source areas on global dust aerosol: results from a model study, J. Geophys. Res. 107 (D21) (2002) AAC14.1-AAC14.27, ISSN: 0148-0227.

[13] U. Ruth, D. Wagenbach, J.P. Steffensen, M. Bigler, Continuous record of microparticle concentration and size distribution in the central Greenland NGRIP ice core during the last glacial period, J. Geophys. Res. 108 (D3) (2003) 4098, doi:10.1029/ 2002JD002376.

[14] B. Delmonte, J.R. Petit, K.K. Andersen, I. Basile-Doelsch, V. Maggi, V.Y. Lipenkov, Dust size evidence for opposite regional atmospheric circulation changes over East Antarctica during the last climatic transition, Clim. Dyn. 23 (3-4) (2004) 427-438.

[15] P. Gabrielli, J.M.C. Plane, C.F. Boutron, S. Hong, G. Cozzi, P. Crutzen, P. Cescon, C. Ferrari, J.R. Petit, V.Y. Lipenkov, C. Barbante, A climatic control on the accretion of meteoric and super-chondritic iridium-platinum to the Antarctic ice cap, Earth Planet. Sc. Lett.

[16] G. Krinner, C. Genthon, Tropospheric transport of continental tracers towards Antarctica under varying climatic conditions, Tellus, B 55 (1) (2003) 54-70.

[17] D.J. Lunt, P.J. Valdes, Dust transport to Dome C, Antarctica, at the last glacial maximum and present day, Geophys. Res. Lett. 28 (2001) 295-298.

[18] K. Wedepohl, The composition of the continental crust, Geochim. Cosmochim. Acta 59 (7) (1995) 1217-1232. 
[19] P. Gabrielli, F.A.M. Planchon, S. Hong, K.H. Lee, S.D. Hur, C. Barbante, C.P. Ferrari, J.R. Petit, V.Y. Lipenkov, P. Cescon, C.F. Boutron, Trace elements in Vostok Antarctic ice during the last four climatic cycles [rapid communication], Earth Planet. Sci. Lett. 234 (2005) 249-259.

[20] M.-L. Siggaard-Andersen, J.P. Steffensen, H. Fischer, Lithium in Greenland ice cores measured by ion chromatography, Ann. Glaciol. 35 (2002) 243-249.

[21] G. Littot, R. Mulvaney, R. Röthlisberger, R. Udisti, E.W. Wolff, E. Castellano, M. de Angelis, M. Hansson, S. Sommer, J.P. Steffensen, Comparison of analytical methods used for measuring major ions in the EPICA Dome C (Antarctica) ice core, Ann. Glaciol. 35 (2002) 299-305.

[22] E. Wolff, H. Fischer, F. Fundel, U. Ruth, B. Twarloh, G. Littot, R. Mulvaney, R. Röthlisberger, M.d. Angelis, C. Boutron, M. Hansson, U. Jonsell, M. Hutterli, F. Lambert, P. Kaufmann, B. Stauffer, T. Stocker, J.P. Steffensen, M. Bigler, M. SiggaardAndersen, R. Udisti, S. Becagli, E. Castellano, M. Severi, D. Wagenbach, C. Barbante, P. Gabrielli, V. Gaspari, Southern Ocean sea-ice extent, productivity and iron flux over the past eight glacial cycles, Nature 440 (7083) (2006) 491-496.

[23] R. Röthlisberger, R. Mulvaney, E.W. Wolff, M.A. Hutterli, M. Bigler, S. Sommer, J. Jouzel, Dust and sea salt variability in central East Antarctica (Dome C) over the last 45 kyrs and its implications for southern high-latitude climate, Geophys. Res. Lett. 29 (20) (2002) 1963, doi:10.1029/2002GL015186.

[24] P. Gabrielli, C. Barbante, C. Boutron, G. Cozzi, V. Gaspari, F. Planchon, C. Ferrari, C. Turetta, S. Hong, P. Cescon, Variations in atmospheric trace elements in Dome C (East Antarctica) ice over the last two climatic cycles, Atmos. Environ. 39 (2005) 6420-6429.

[25] F.A. Planchon, C.F. Boutron, C. Barbante, E.W. Wolff, G. Cozzi, V. Gaspari, C.P. Ferrari, P. Cescon, Ultrasensitive determination of heavy metals at the sub-picogram per gram level in ultraclean Antarctic snow samples by inductively coupled plasma sector field mass spectrometry, Anal. Chim. Acta 450 (1-2) (2001) 193-205.

[26] M. Legrand, P.A. Mayewski, Glaciochemistry of polar ice cores: A review, Rev. Geophys. 35 (1997) 219-243.

[27] H. Holland, The Chemical Evolution of the Atmosphere and Oceans, Princeton Univ. Press, Princeton, NJ, 1984.
[28] E. Arnold, J. Merrill, M. Leinen, J. King, The effect of source area and atmospheric transport on mineral aerosol collected over the North Pacific Ocean, Glob. Planet. Change 18 (3-4) (1998) 137-159.

[29] L. Johnson, Particle-size fractionation of eolian dusts during transport and sampling, Mar. Geol. 21 (1976) M17-M21.

[30] M. Hansson, Are changes in atmospheric cleansing responsible for observed variations of impurity concentrations in ice cores? Ann. Glaciol. 21 (1995) 219-224.

[31] J. Schwander, J. Jouzel, C.U. Hammer, J.-R. Petit, R. Udisti, E. Wolff, A tentative chronology for the EPICA Dome Concordia ice core, Geophys. Res. Lett. 28 (22) (2001) 4243-4246.

[32] A. Correia, R. Freydier, R.J. Delmas, J.C. Simes, J.-D. Taupin, B. Dupr, P. Artaxo, Trace elements in South America aerosol during 20th century inferred from a Nevado Illimani ice core, Eastern Bolivian Andes (6350 m asl), Atmos. Chem. Phys. 3 (5) (2003) 1337-1352.

[33] M. Legrand, C. Lorius, N. Barkov, V. Petrov, Vostok (Antarctica) ice core: atmospheric chemistry changes over the last climatic cycle (16,000 years), Atmos. Environ. 22 (2) (1988) 317-331.

[34] R. Röthlisberger, R. Mulvaney, E.W. Wolff, M.A. Hutterli, M. Bigler, M.d. Angelis, M.E. Hansson, J.P. Steffensen, R. Udisti, Limited dechlorination of sea-salt aerosols during the last glacial period: Evidence from the European Project for Ice Coring in Antarctica (EPICA) Dome C ice core, J. Geophys. Res. 108 (D16) (2003) 4526, doi:10.1029/2003JD003604.

[35] V. Gaspari, C. Barbante, G. Cozzi, P. Cescon, C. Boutron, P. Gabrielli, G. Capodaglio, C. Ferrari, J. Petit, B. Delmonte, Atmospheric iron over the last deglaciation: Climatic implications, Geophys. Res. Lett. 33.

[36] B. Stenni, V. Masson-Delmotte, S. Johnsen, J. Jouzel, A. Longinelli, E. Monnin, R. Röthlisberger, E. Selmo, An oceanic cold reversal during the last deglaciation, Science 293 (2001) 2074-2077.

[37] F. Parrenin, J.-M. Barnola, J. Beer, T. Blunier, E. Castellano, J. Chappellaz, G. Dreyfus, H. Fischer, S. Fujita, J. Jouzel, K. Kawamura, B. Lemieux, L. Loulergue, V. MassonDelmotte, B. Narcisi, J.-R. Petit, G. Raisbeck, D. Raynaud, U. Ruth, J. Schwander, M. Severi, R. Spahni, J.P. Steffensen, A. Svensson, R. Udisti, C. Waelbroeck, E. Wolff, The EDC3 chronology for the EPICA Dome C ice core, Clim. Past Discuss. 